\title{
Applying Community-Driven Approaches to Rural Development and Women's Empowerment in Afghanistan
}

\author{
Abdul Jamil Ziaey
}

Community-driven approaches have become popular in the development field over recent years. By establishing community development councils (CDCs), this approach enables strong community engagement in the projects' design and execution while proactively promoting women's participation, leading both to improved service delivery and effective implementation of more sustainable projects. In addition, using a community-driven approach in the implementation of rural development programs in least developed and post-conflict societies can help with raising awareness about democratic processes. In Afghanistan, two national programs, the National Solidarity Program (NSP) and the Citizens' Charter National Priority Program (CCNPP), embraced a CDD approach in the implementation of their projects. RCT studies indicate that the NSP has been one of the most successful programs in the country while reports, so far, indicate the same about the CCNPP. Both programs have made an impact by creating gender-balanced CDCs through elections based on secret voting and universal suffrage. These programs have significantly contributed to the enhancement of women's participation in the society. Nonetheless, maintaining this progress requires a stable, supportive socio-political environment in the long run. Policymakers should consider the successes and difficulties related to the NSP and CCNPP when creating community-driven approaches to development in the future.

https://doi.org/10.4079/pp.v28i0.9 


\begin{abstract}
ABDUL JAMIL ZIAEY is a Fulbright student pursuing his graduate studies in Public Policy with a concentration on International Development at the George Washington University. He has previously worked with NGOs and INGOs working for development in Afghanistan. Currently, he is serving as a Research Fellow on counter terrorism at 'Rise to Peace', a non-profit organization based in Washington DC.
\end{abstract}

\title{
ACKNOWLEDGEMENTS
}

The author owes the Fulbright Program a great deal for making this educational opportunity possible for him. He offers his sincere gratitude to Professor Joan-Dudik Gayoso for her thorough and insightful guidance and comments from the very beginning of writing this paper to the very end. The author also gives heartfelt thanks to Mr. Alex Borkholder, the Policy Perspectives' Associate Editor, for his thoughtful, constructive feedbacks and his enthusiasm, honesty, and hard work in editing this paper. Last but not least, the author is grateful to Ahamd Saleem, the then Director-General of the CCNPP Program, for taking his time to participate in an interview and add to the paper by sharing his knowledge and experience. 


\section{OVERVIEW}

Afghanistan is a war-torn, underdeveloped country located on the border of Central and South Asia. Eighty percent of its population lives outside the regional and provincial centers (Beath, Christia, and Enikolopov 2015). The country has experienced much political turmoil within the past four decades, from the Soviet Union's invasion to the current resistance war against the Taliban. Three years after the Soviets' withdrawal, the Mujahideen groups (political Islamists fighting the Soviets in Afghanistan) caused the communist regime they supported to collapse in 1992 (Katzman and Thomas 2017). However, the conquering Mujahideen groups could not agree on establishing a central, united government and the conflicts among them kept the country in political turmoil for many more years. The chaotic political situation paved the way for the emergence of the Taliban, which ruled over most parts of the country from 1996 to 2001 (Maizland and Laub 2020). The Taliban's Islamic jurisprudence, influenced by the Wahabi interpretations of Islam mixed with Pashtuns' pre-Islamic tribal code, imposed strict limitations on civil liberties for all people, particularly women, who were required to wear Chadri (the head-to-toe Burqa) (Maizland and Laub 2020). The September 11 attacks on the United States, organized by Osama bin Laden's Afghanistan-based Al-Qaeda, brought the country to the center of global attention. In retaliation to the attacks, US troops, together with The Northern Alliance resistance group, defeated Osama bin Laden and his Afghan supporting regime (the Taliban) in 2001 (Katzman and Thomas 2017).

After the establishment of a new post-conflict regime with democratic structures, the international donor community poured immense amounts of aid into the country for reconstruction. The overall goals of the new Afghan government included strengthening democratic institutions, fighting terrorism, rebuilding the country's infrastructure, and ensuring civil and political rights-with an emphasis on empowering women to be involved in socio-political and economic arenas (UN 2001). This paper focuses on the impact of community-driven development as it involves women and promotes their role in the new democratic government formed following the end of the Taliban rule. Although there are legitimate questions about the impact of aid provided to Afghanistan, they are outside the scope of this analysis.

The country has implemented two substantial national programs that serve as examples of successful development efforts. Launched in 2003 and completed in 2016, the National Solidarity Program (NSP) is by far the largest development program in Afghanistan. The NSP was administered by the Afghan government and funded by the World Bank to develop and rehabilitate villages throughout the country. Building upon the NSP, the country initiated the Citizens' Charter National Priority Program (CCNPP) in 2017, intending for it to serve Afghan citizens for ten years (National Priority Programs n.d.). The CCNPP is intended to continue to provide basic services to Afghan citizens based on community priorities. Both programs have embraced a communitydriven approach in their development activities hoping to create opportunities for upward social mobility and positive economic change. Using this approach, both programs aim to give the ownership of development projects to grassroots communities by establishing Community Development Councils (CDCs) that make the efforts case-specific and compatible within the local context. 
This paper argues that using a community-driven approach in development programs in Afghanistan has improved not only the projects' implementation and effectiveness but also the communities' general social and economic mobility. The concept of mobility is generalizable to using aid in a way that increases individuals' overall understanding of their social and economic status, irrespective of gender, and prompting them to "move between classes" as well as take on other activities that are economically beneficial to both them and their communities (WEF 2020). For the purpose of this paper, the focus on social mobility specifically refers to increasing and enforcing women's participation in development programs and other social activities.

\section{COMMUNITY-DRIVEN APPROACH THEORY}

Although the terms "community-based" and "community-driven" may sometimes be used interchangeably, the concept of the community-driven approach is a modified version of the community-based approach. While the community-based approach emphasizes the involvement of communities in the design and management of projects, the community-driven approach calls for communities directly controlling key project decisions, including management of investment funds (Mansuri and Rao 2004). In practice, the distinction between the two approaches is blurred and many projects may contain some components of both (Pozzoni and Kumar 2005). Regardless of this distinction, both are participatory approaches that emphasize agency and participation of grassroots communities in development projects.

Community-driven approaches originated as a method for dealing with issues rooted in macro-politics and macro-economics (i.e., fighting colonialism, changing economic dynamics nationally), and evolved to be applied to small-scale development projects. For example, according to Mansuri and Rao (2004), the community-driven approach initially served an anti-colonial purpose, such as the approach seen in Gandhi's movement that stressed self-reliance in villages. Later on, especially in the 1980s, prescribing local management of resources and decisions became a popular way for the development field to remedy the ineffectiveness of government-led development programs.

When looking into participatory approaches, it is important to distinguish between community participation and citizen participation. While community participation refers to beneficiaries' engagement in a project's decision-making processes (Pozzoni and Kumar 2005), citizen participation concerns participatory governance, such as engaging citizens in policymaking processes. Institutionally, Community Development Councils (CDCs) represent community participation, while Civil Society Organizations represent citizen participation in most countries.

At its core, the community-driven approach is about encouraging people to organize themselves, identify problems, create a plan to solve those problems, and execute those plans using community resources or resources from assisting external organizations (Matsheng 1971). Following this description, people at the grassroots level are the real decision-makers and implementers while the government and aid agencies act only as facilitators and resource provisioners. 
Despite its theoretical appeal, this picture may not be very illustrative of what actually happens in the real world. While a key objective of the community-driven approach is the integration of authentic local knowledge into projects' decision-making processes, in practice, outside agendas are often expressed as "local knowledge" and the concept of participation is used to legitimize those agendas in order to meet the reporting requirement of donors (Mansuri and Rao 2004, 7).

Generally, using the community-driven approach in the implementation of development projects is in the best interest of both aid recipients and aid providers. It creates community confidence in their own abilities, fostering a sense of responsibility which motivates community members to strive for and accomplish greater things for themselves (Matsheng 1971). Communitybased approaches can be a mechanism to increase sustainability by building capacity, improving efficiency and effectiveness, making development more inclusive, and empowering the poor by making the allocation of development funds more responsive to their needs (Mansuri and Rao 2004).

In this context, the attitude of development specialists is important. Development professionals emphasize that people involved in the development work, especially with a Community-Driven Development (CDD) approach, should be highly motivated to serve humanity and work for communities (Saleem 2020). Personal traits of a development worker in this field are sometimes more important than professional expertise and education; qualities like patience, integrity, and devotion can make a difference in achieving the goals of a CDD-type program in the developing world. Similarly, personal attitudes of development professionals toward women matter in how effectively the women's empowerment processes can take place and develop.

Assessing the cost effectiveness of programs like these is an open question and depends on a project's objectives. Not all development interventions have community development as the main goal. This makes evaluation of cost effectiveness dependent on whether or not a project puts a monetary value on changes in social mobility, increased women's participation, and other aspects of community development. Although studies suggest that CDD-type interventions will lead to more sustainable outputs (Dongier et al. 2002), the academic literature does not suggest that such programs cost less than those that do not place a value on elements of community development. Yet, deciding whether to put a monetary value on the benefits of increased community action and women's engagement achieved by CDD-type interventions may change how critics interpret the costs and benefits of these programs.

Concerningly, evidence indicates that in CDD-type projects, costs and benefits are distributed unequally and are skewed in favor of wealthier individuals rather than the poor (Pozzoni and Kumar 2005). According to the World Bank, "dimensions of inclusion" explain the underlying reasons behind unequal distribution of costs and benefits (Post and Agarwal n.d.). There are at least two types of inclusion: formal and substantive. Formal inclusion refers to being able to gain access to the decision-making venues, whereas substantive inclusion refers to the ability to voice opinions that are taken into consideration by participants (Pozzoni and Kumar 2005). Just as outside agendas may drown out local ideas, the elites and more powerful participants are also likely to overwhelm the voices of weaker groups as they speak up with a different perspective. In reality, effective participation may require standing in opposition to the interests of 
powerful groups. For this reason, both project targeting and quality may tend to be markedly worse in more unequal communities (Mansuri and Rao 2004).

Checks and balances can help to maximize the role of less privileged minorities when implementing CDD. One critical method is to take into account the social and cultural context within which beneficiaries live and organize themselves by putting greater emphasis on contextualized project designs (Mansuri and Rao 2004). For example, development professionals can focus on designing projects which ensure the equal participation of women in communities where they are not typically represented. Taking context into account is likely to contribute both to smooth implementation of projects as well as their sustainability and impact. However, this approach requires more time and may slow down efforts to respond to the urgent needs of wartorn communities (Bouta, Frerks, and Bannon 2005). Furthermore, adopting a community-driven approach requires a supportive institutional environment in which governments operate as enablers of development processes rather than as implementers (Thompson 1995).

Lastly, community leaders must be held accountable to project beneficiaries rather than bureaucratic superiors (Mansuri and Rao 2004). Establishing a bottom-up approach to accountability is difficult and time consuming to achieve compared to only holding leaders accountable. Instead, introducing a professionally designed system of accountability directed toward all stakeholders would have potential for ensuring transparency and effectiveness in development projects.

\section{CDD AND MOBILITY THEORY}

Generally, social scientists support the idea that a positive association exists between social mobility and economic development (Kingsley 1962 as cited in Goldthorpe 1985). Yet, socioeconomic mobility happens at different rates in different societies. Specifically, countries at the bottom of the development scale show slower mobility patterns than countries in the middle of the scale (Clark 2016). In the least developed societies, social mobility and economic development often do not occur together. These countries may grow economically without support for women's engagement and social equality, hindering sustainable growth levels in the long run.

Adopting a CDD approach can encourage more gender-balanced representation in local decision-making processes (Bouta, Frerks, and Bannon 2005). Women's involvement in planning, implementing, and managing sub-projects leads to their economic, political, and social empowerment - a key indicator of social mobility in rural areas. According to the World Bank (n.d.), women's empowerment is both a process and an outcome in the community-driven approach to development. Women benefit from the results of the development projects, the community's attitudes toward women improve, and women gain confidence in their ability to influence local decision-making.

One concrete example of socio-economic mobility that results from adopting a CDD approach is when the community-based organizations (CBOs) include CDCs. Although community organizations in general have existed for a long time and have supported social transformations, the CDD approach establishes CBOs as special local institutional structures with specific functions. Today, CBOs provide local institutional support towards the implementation of 
donor-assisted development projects and can be recognized as potential agents of change (Opare 2007). The main characteristics of CBOs are that they are locally formed, locally staffed, and their activities are specific to the communities in which they operate (Divyathejomurthy 2016). The community-restricted nature of CBOs differentiates them from the civil society organizations and non-governmental organizations (NGOs) that have a wider geographic reach (Opare 2007). Typically, members of the CBOs are elected by community members and emphasize promoting women's roles and participation.

As CBOs possess knowledge of local circumstances, supporting these organizations will help mobilize local resources for grassroots development. In addition, they can play an active role in generating more inclusive decision-making processes and limiting the dominance of local elites in community affairs (Opare 2007). However, obtaining such a level of inclusivity in decisionmaking depends on the extent of the elites' influence on the CBOs. In post-conflict societies, nurturing these institutions and processes can help "reweave the torn social fabric and support positive social capital by...strengthen[ing] social cohesion and inclusion" (Bouta, Frerks, and Bannon 2005, 124). In fact, according to a World Bank paper on women's empowerment (n.d.), "empowering communities to take control of their own development (development of community) is both the means to achieve better development outcomes and an outcome in its own right" (6). However, scholars also claim that the development of community is likely to lead to development in community with respect to economic growth and improved social welfare (Summers 1986).

The World Bank (n.d.) also notes that increasing women's participation in rural projects is a long-term endeavor and does not necessarily translate into lasting (or early) change in rural decision-making or social norms. Understanding power relationships within the communities is important, especially when designing projects to maximize inclusion of women and other socially under-represented groups. Due to numerous constraints, such as women's lack of confidence, the dominant patriarchal attitudes, and social norms in the majority of rural areas, development researchers and practitioners cannot safely assume that women would be willing and able to take part in decision-making processes to the best of their abilities (Bouta, Frerks, and Bannon 2005). Careful contextualization of processes and mobilizing male support for women's participation can help ensure women's sustainable engagement in the community (Bouta, Frerks, and Bannon 2005). Projects also need to comprehensively measure how activities change women's lives instead of simply relying on tracking outputs, such as the number of women who received credit, for example (World Bank n.d.).

Guided by the theoretical findings above, the following sections will review the approach and accomplishments of Afghanistan's two national development programs, the NSP and the CCNPP.

\section{AFGHANISTAN NATIONAL PROGRAMS: APPROACH AND ACCOMPLISHMENTS}

\section{NATIONAL SOLIDARITY PROGRAM}

The National Solidarity Program (NSP), launched in 2003, has been by far the largest development program in Afghanistan, ending in 2016 after three phases that cost a total of \$2.5 
billion (Katz 2017). The World Bank and a consortium of bilateral donors funded the program, and the Ministry of Rural Rehabilitation and Development administered it in collaboration with eight national and 21 international NGOs as facilitating partners (Beath, Christia, and Enikolopov 2015).

The NSP implemented roughly 65,000 projects in approximately 32,000 communities (Groe 2015). Results from a randomized controlled trial evaluation conducted by International Peacekeeping show that the NSP had positive effects on access to drinking water and electricity, acceptance of democratic processes, perceptions of economic well-being, and attitudes toward women and their participation in public affairs (Beath, Christia, and Enikolopov 2015).

The NSP exemplifies a CDD program in which communities had meaningful ownership of the projects and their processes; as Katz (2017) states, "[t]he NSP sought the development of communities through its development activities in communities" (13). The program's implementation followed five transformative action-learning phases: raising communities' awareness; electing the CDCs (or CBOs, as discussed above); preparing a Community Development Plan; designing projects and submitting project proposals; and implementing, monitoring, and evaluating projects (Affolter et al. 2009). Proposals submitted by CDCs in all 34 provinces were funded through block grants valued at $\$ 200$ per household and $\$ 60,000$ maximum for each village that met the criteria (Beath, Christia, and Enikolopov 2015).

Owing to its community-driven approach, the NSP ushered in a new phase in the relations between the central government and the local communities. The program's participatory approach to local government, particularly its democratically elected CDCs, offered an inclusive learning opportunity about democratic practices for the rural communities (Boesen 2004). The concept and practice of secret-ballot elections as exercised in CDCs' elections arguably contributed to the establishment and promotion of representative and service-oriented local governance structures in the rural areas (Affolter et al. 2009). However, it would be more accurate to say that it contributed to the introduction of the new local governance structures rather than their institutionalization.

The NSP's mobilization process for participation spurred communities' willingness to cooperate and to contribute to reconstruction with a long-term goal of self-reliance (Boesen 2004). The increased sense of cooperation as a result of implementation of the program implies that not all villagers in every community had a prior sense of cooperation. This situation, to some extent, reflects the concerns expressed by Katz (2017), that practitioners assume the presence of a community while communal bonds are often absent, weak, or channeled in destructive ways. Boesen (2004) reflects on what the designers of the program were initially hoping to achieve (i.e. communities' enhanced willingness to cooperate), however, Katz underscores that community building requires an independent process that should come prior to community-based development work.

The NSP's CDD approach was transformative, challenging some of the fundamental social norms in Afghanistan - especially in regard to gender relations and local-level power structures (Boesen 2004). Establishing gender-balanced, democratically elected CDCs based on universal suffrage is a significant, albeit cautious, step forward in creating real transformation of those norms. However, most social and political transformations require time as well as a stable, 
enabling political environment to become entrenched in the society (Boesen 2004). Thus, taking into account the country's fragile security situation, it may be still too early to determine the impacts with a high level of confidence.

The preliminary positive effects of NSP on acceptance of democratic norms and female participation suggest that mandating such practices by development programs may spur social change (Beath, Christia, and Enikolopov 2015). However, as Regt, Majumdar, and Singh (2013) quote from a respondent, "CDD is not a strategy but a tactic" (36). That is, CDD is an approach to change but it is not in itself a strategy for development. "Sensitivity to context, long- and shortterm, will in turn argue for flexibility and contingencies in the design" (Regt, Majumdar, and Singh $2013,36)$. In the case of NSP, the level of the program effects varied in different parts of the country, especially in regard to social mobility and the social traditions embedded in certain communities. For example, female CDCs in Kandahar, a Southwestern province, frequently rated their mind-change assessment lower than their counterparts in Herat and Balkh and doubted that the male community members would welcome their social participation (Affolter et al. 2009). This indicates that development and social change require participation of all stakeholders in communities and do not occur by only implementing CDD projects.

Finally, CDCs are likely to be problematic in some areas of the country as they challenge the informal local governance structures called Jirga or Shura (Farsi words meaning 'council'). Such groups have existed for a long time and are led by local elites; there is little regard for accountability and transparency or focus on inclusion and equality. Akbari and Rahmani (2020) suggest converting CDCs to Village Councils (VCs), defined as subnational government structures in the constitution, for their protection. However, CDCs already have a legal basis in Afghanistan under a CDCs by-law, which also labels them as Shuras (MRRD 2006). Regardless, it is important to empower communities to drive the reconstruction process in close collaboration with local states (Regt, Majumdar, and Singh 2013). Although doing so may not change the circumstances overnight, it could result in the long-term support of these structures by the national government.

\section{CITIZENS' CHARTER NATIONAL PRIORITY PROGRAM}

Launched in 2017, Citizens' Charter National Priority Program (CCNPP) is one of Afghanistan's national priority programs (National Priority Programs n.d.). It is funded by the Afghanistan Reconstruction Trust Fund (ARTF) and the World Bank. The CCNPP builds on the NSP's experience with a CDD approach. Its focus goes beyond supporting the planning and implementation of development projects; according to a pamphlet on national priority programs by the Afghan Ministry of Finance, the goal of the CCNPP is to improve service delivery to reduce poverty and deepen the relationship between citizens and the state through strengthened CDCs (National Priority Programs n.d.). The Ministry of Rural Rehabilitation and Development (MRRD) and the Independent Directorate for Local Governance (IDLG) are implementing the program in an effort to make service delivery more effective and citizen centric (MRRD and IDLG 2019a). Fundamentally, this program is response to community priorities, serving as a commitment to provide all citizens in Afghanistan with basic services.

CCNPP, with a 10-year budget of \$628 million, has reached over 13 million beneficiaries in approximately 12,850 communities countrywide (CCNPP 2020). It has supported the successful 
election of around 12,800 CDCs where women account for half of the elected members; it has also financed over 10,500 sub-projects based on community priorities. CCNPP's website provides upto-date details about their work progress and key project indicators.

According to the MRRD and IDLG (2019b), the CCNPP covers capacity building of CDCs and other grassroots institutions as well as thematic studies and evaluations, including learning activities from the village level to the national level. Due to an extra emphasis on gender and social inclusion in CCNPP, CDCs are increasingly at the center of the program's attention.

"The extent to which [CDCs] are effective is based on a number of interrelated factors: they must reflect citizens' priorities, have the support of senior management and staff, and include a well-functioning grievance redress mechanism" (Post and Agarwal n.d., 11). CCNPP has reported satisfactory performance in relation to all these factors. However, lack of awareness and functionality of certain sub-committees are still key challenges for the program. Furthermore, despite NSP's CDD activities for almost 15 years, CCNPP still reports challenges regarding female participation in social activities in different parts of the country. Based on a 2019 Citizens' Charter quarterly report, this is due both to insecurity and social norms, exacerbated by difficulty with recruiting female social organizers. This is a clear example of how the lack of a wider, enabling political environment affects the implementation of CDD projects and the accomplishment of its goals. Changes in the overall security and political situation of the country could reverse the progress made so far.

The political context in which Citizens' Charter is operating is substantially different from that of the NSP. Since the CCNPP began, the country has been in political turmoil and the security situation has been deteriorating. The Taliban and other insurgent groups have taken control of many rural areas or have eroded the security situation of these regions. This situation is in stark contrast to the situation in which the NSP was operating, particularly in its first phase. Yet, CCNPP is operating with the same standards and achieving more in terms of community participation, women's engagement, and socio-political transformation of local areas-indicating huge accomplishments by both CDD-based programs over the last two decades.

According to Ahmad Saleem, a former director-general of CCNPP, the following lessons learned from NSP now make CCNPP distinct in many aspects (Saleem 2020):

- "The infrastructure projects menu was open in the NSP, but CCNPP [is] restricted to only four sectors: clean drinking water, rural roads, irrigation canals, and electricity."

- "The provision of clean drinking water to a CCNPP community is a must. Any other infrastructure projects follow after it. In NSP, it was just like any other service delivery project."

- "The energy projects are only on renewable sources. Fuel electric generator projects that were once common in NSP are not in practice anymore."

- "Women's participation in CCNPP CDCs is mandatory; without women's participation, the community does not get the financial resources."

- "The CCNPP also covers the urban population, while NSP was only for rural areas."

- "The local administrators in the rural districts and cities are part of the program. For instance, the district governor is the chairperson of the District Citizen Charter 
Management Committee, a committee that oversees the program implementation in a district. There are similar committees at the province level and municipality level."

Thus, some of these changes are related to priorities in the type of services, like securing clean drinking water, while some of the other changes concern governance and participation issues, such as emphasizing women's participation and strengthening community-based structures through systematically involving local government in the program operations.

\section{CONCLUSION AND POLICY RECOMMENDATIONS}

The community-driven approach is arguably the most popular approach to implementing development projects around the world. CDD has significant advantages that help make multidimensional development possible. In Afghanistan, CDD principles have guided two of the largest national programs, NSP and CCNPP, and led to greater community participation and more effective women's involvement, particularly in project activities but also more generally throughout society.

Combined, the NSP and CCNPP programs have facilitated around 75,500 projects based on community priorities that have been proposed, designed, and implemented by Community Development Councils. This process has enabled people to identify their needs and set priorities collectively based on their own assessments. Additionally, communities have democratically elected around 45,000 CBOs or CDCs in which women account for roughly half of the members. CDC elections provide a chance for men and women in rural areas to learn the process of and realize the purpose of democratic elections, which then lead to their participation in parliamentary and presidential elections.

Taking the success of these two CDD programs into account, policymakers should think of such strategies to bring about social mobility and economic development in underdeveloped post-conflict societies. Both programs have established thousands of CDCs that have successfully implemented tens of thousands of development projects. Nonetheless, the challenges these programs have faced show that while identifying key stakeholders may be simple, tailoring projects that make their engagement supportive of women and marginalized groups is still difficult. This paper suggests considering the following points to achieve smoother implementation of CDD programs.

First, Afghan citizens need a more supportive political environment. An environment that is supportive of CDD programs is essential to protect the processes as well as the outcomes in the long run. In the case of Afghanistan, for instance, the ongoing peace talks and the resulting political system will affect the functionality of CDCs and the role of women in decision-making processes in the future. A CDD approach may never be possible if security is not assured.

Second, CDD administrators need to approach community development holistically. Implementing CDD projects is not the only goal of community development. Rather, development programs need to empower communities and create a sense of interconnectedness through their interventions and implementation processes. CDD programs need to bring about development in communities through the development of communities. 
Third, CDD projects need to identify development practitioners with a unique combination of leadership and social skills. Identifying complex power relationships, sensitivities, and social intricacies in each community are key for the success of CDD programs and practitioners must use caution with how they handle such situations.

Finally, project administrators need to be creative and flexible in designing and implementing projects. Since challenges vary across different communities, strategies need to be adaptable. As long as the projects stick to the general approaches of CDD and serve the central goals of socio-economic development, there is no need for any single, unchangeable blueprint.

Implementation of the NSP and CCNPP programs with a CDD approach have contributed to significant changes in socio-economic mobility and women's empowerment in Afghanistan over the past two decades. Nonetheless, sustaining these changes will depend on the changes in the country's political system following the ongoing peace talks and in the national security situation. With a supportive national environment, implementing further CDD-type interventions could lead to substantial socio-economic accomplishments in the future. 


\section{REFERENCES}

Affolter, Friedrich W, Katja Richter, Karimullah Afaq, Assadullah Daudzai, M. Taofiq Massood M., Niamatuallah Rahimi, and Ghotai Sahebian. 2009. "Transformative Learning and Mind-Change in Rural Afghanistan.” Development in Practice 19, no. 3: 311-328.

Akbari, Mohammad A., Rahmani Obaidullah. 2020. "The Performance Review of the Community Development Councils from Perspective of Local Governance in Afghanistan." International Journal of Education and Research 8, no. 1.

Beath, Andrew, Fotini Christia, and Ruben Enikolopov Ruben. 2015. "The National Solidarity Programme: Assessing the Effects of Community-Driven Development in Afghanistan." International Peacekeeping 22, no. 4: 302-320.

Boesen, Inger W. 2004. "From Subjects to Citizens: Local Participation in the National Solidarity Programme.” Afghanistan Research and Evaluation Unit.

Bouta, Tsjeard, Georg Frerks, and Ian Bannon. 2005. "Gender and Community-Driven Development." World Bank.

Clark, Rob. 2016. "Examining Mobility in International Development." Social Problems 63, no. 3: 329-350.

Citizen's Charter National Priority Program (CCNPP). 2020. "Progress to date: Key Indicators." Retrieved from http://www.ccnpp.org/Default.aspx?\#Key.

De Regt, Jacomina, Shruti Majumdar, and Janmejay Singh. 2013. "Designing CommunityDriven Development Operations in Fragile and Conflict-Affected Situations: Lessons from a Stocktaking." World Bank.

Divyathejomurthy, V. 2016. "Community Based Organizations And Rural Development." International Research Journal of India 2, no 3. ISSN 2454-8707.

Dongier, P, Julie Van Domelen, Elinor Ostrom, Andrea Ryan, Wendy Wakeman, Anthony Bebbington, Sabina Alkire, Talib Esmail, and Margaret Polski. 2002. "Community-Driven Development”. In Core Techniques and Cross-Cutting Issues. Retrieved from http://documents 1.worldbank.org/curated/en/399341468761669595/pdf/wps3209commu nity.pdf.

Groe, Katie. 2015. "National Solidarity Program Creates Infrastructure in Rural Afghanistan." The Borgen Project. Retrieved from www.borgenproject.org. 
Katz, David J. 2017. "Community-Based Development in Rural Afghanistan: First Assume a Community." Peaceworks no. 127. United States Institute of Peace.

Katzman, Kenneth, and Clayton Thomas. 2017. "Afghanistan: Post-Taliban Governance, Security, and U.S. Policy.” Congressional Research Service. Retrieved from www.crs.gov.

Kingsley, Davis. 1962. "The Role of Class Mobility in Economic Development." Population Review 6. Quoted in Goldthorpe, John H. 1985. "On Economic Development and Social Mobility”. The British Journal of Sociology 36, no. 4: 549-573.

Maizland, Lindsay and Zachary Laub. 2020. "The Taliban in Afghanistan.” Council on Foreign Relations. Retrieved from www.cfr.org.

Mansuri, Ghazala, and Vijayendra Rao. 2004. "Community-Based and -Driven Development: A Critical Review." The World Bank Research Observer 19, no. 1: 1-39.

Matsheng, J.S. 1971. "The Community Approach to Rural Development." Botswana Notes and Records 3: 195-197.

Ministry of Rural Rehabilitation and Development (MRRD). 2006. "Community Development Council By-Law." Retrieved from www.mrrd.gov.af.

Ministry of Rural Rehabilitation and Development (MRRD) and Independent Directorate of Local Governance (IDLG). 2019a. "Environmental and Social Management Framework (ESMF) For the Citizens' Charter Afghanistan Project (CCAP)." Retrieved from www.mrrd.gov.af.

MRRD IDLG. 2019b. “Citizens' Charter Quarterly Progress Report (Fourth Quarter; Reflecting Annual Standing)." Retrieved from www.mrrd.gov.af.

National Priority Programs. n.d. The Joint Coordination and Monitoring Board (JCMB). Retrieved from www.policymof.gov.af.

Opare, Service. 2007. "Strengthening Community-Based Organizations for the Challenges of Rural Development.” Community Development Journal 42, no. 2: 251-264.

Post, David, and Sanjay Agarwal. n.d. "How-To Notes: Citizen Charters: Enhancing Service Delivery through Accountability." World Bank. 
Pozzoni, Barbara, and Nalini Kumari. 2005. "A Review of the Literature on Participatory Approaches to Local Development for an Evaluation of the Effectiveness of World Bank Support for Community-Based and -Driven Development Approaches.” World Bank.

Saleem, Ahmad (Then-General Director, CCNPP Program). 2020. In discussion with the author.

Summers, Gene F. 1986. "Rural Community Development." Annual Review of Sociology 12: 347-371.

Thompson, J. 1995. "Participatory Approaches in Government Bureaucracies: Facilitating the Process of Institutional Change." World Development 23, no. 9: 1521-1554.

The United Nations. 2001. "General Assembly, Plenary Press Release." $56^{\text {th }}$ general assembly plenary, $91^{\text {st }}$ meeting. Retrieved from https://www.un.org/press/en/2001/ga10005.doc.html.

The World Bank. n.d. "Women's Empowerment in Rural Community-Driven Development Projects”. Retrieved from www.worldbank.org

World Economic Forum (WEF). 2020. "The Global Social Mobility Report 2020: Equality, Opportunity and a New Economic Imperative.” Retrieved from http://www3.weforum.org/docs/Global_Social_Mobility_Report.pdf. 